\title{
ЯЗЫКОВЫЕ ОСОБЕННОСТИ НАЦИОНАЛЬНО-КУЛЬТУРНОЙ СПЕЦИФИКИ ЭРГОНИМОВ
}

\section{LANGUAGE FEATURES OF THE NATIONAL-CULTURAL SPECIFICITY OF ERGONYMS}

\section{K. Taghiyeva}

Summary: Special names are of great importance in cultural communication, in the study of the culture and traditions of other peoples, and in the study of the interrelation of language and culture as a whole. Special names are the guardians of the material and spiritual cultural images of a particular community. They reflect the national and cultural symbols, stereotypes, standards, traditions and worldviews of language speakers. Ergonomics, a type of proper name, are the best source of information about national culture. In this case, it is possible to better understand the cultural priorities and the spiritual world of the national-cultural community. Without knowing the national-cultural background of ergonim, it is impossible for it to be understood by a native speaker and a representative of a foreign culture. The study studies the linguistic manifestations of the national-cultural specifics of ergonims. Samples of Azerbaijan's national and cultural heritage are taken here as sources of ergonomics. The methodological basis of the research consists of descriptive and semantic methods, the method of component analysis. The study identifies the compatibility of ergonomics with Azerbaijani linguocultural concepts and describes the preservation of this information. Here, the ergonomic space of Azerbaijan is considered from the linguocultural position.

Keywords: special name, ergonym, cultural heritage, linguoculturology, ergonomic space.

\author{
Тагиева Кенуль Арзу гызы \\ старший преподаватель, Азербайджанский \\ государственный аграрный университет \\ konul.t@rambler.ru
}

Аннотация: Собственные имена имеют большое значение в культурном общении, в изучении культуры и традиций других народов, а также в изучении взаимосвязи языка и культуры в целом. Собственные имена - хранители материальных и духовных культурных образов конкретной общины. Они отражают национальные и культурные символы, стереотипы, стандарты, традиции и мировоззрение носителей языка. Эргономика - вид собственного имени, лучший источник информации о национальной культуре. В этом случае можно лучше понять культурные приоритеты и духовный мир национально-культурного сообщества. Не зная национально-культурного фона эргономики, его невозможно понять носителю языка и представителю иностранной культуры. В исследовании изучаются языковые проявления национально-культурной специфики эргонимов. Образцы национального и культурного наследия Азербайджана взяты здесь как источники эргонимов. Методологическую основу исследования составляют описательный и семантический методы, метод компонентного анализа. В исследовании определяется совместимость эргонимов с азербайджанскими лингвокультурными концепциями и описывается сохранение этой информации. Здесь эргономическое пространство Азербайджана рассматривается с лингвокультурологической позиции.

Ключевые слова: собственное имя, эргоним, культурное наследие, лингвокультурология, эргономическое пространство.

нентного анализа. В основе исследования лежит терминология Н. В. Подольской [7].

При изучении эргонимов можно выявить не только специфику их смысловой структуры и механизма формирования, но и лингвокультурную информацию.

Несмотря на культурное разнообразие народов мира, культурное наследие, национальные и духовные ценности являются одним из важных средств их объединения. У каждого народа есть свое культурное наследие. Это наследие сочетает в себе материальное и духовное культурное наследие, связывает будущее нации с ее историческим прошлым. «Культурное наследие» означает культуру, ценности и традиции: картины, исторические памятники, археологические находки, древние здания, сооружения, различные формы человеческого творчества, древние города, природу, обычаи, церемо- 
нии, передаваемые из поколения в поколение в обществе, применение для общества, традиционные ремесла, рисунки, приемные, знания и навыки, история народа и т. д. Как мы видели, понятие культурного наследия очень широко. Наряду с материальными вещами здесь есть часть духовных элементов. Обладание богатым национальным и духовным наследием, ценностями, выражающими национальную самобытность, всемирно известными образцами материальной и духовной культуры, определяет уникальность каждого народа. Также следует отметить, что каждое общество всегда тщательно выбирает то, что будет передано будущим поколениям.

Конвенция ЮНЕСКО «Об охране всемирного культурного наследия и природных ресурсов» от 16 ноября 1972 г. дает четкое определение термина «культурное наследие»:

В настоящей Конвенции «культурное наследие» означает:

Памятники: произведения архитектуры, монументальной скульптуры и живописи, археологические элементы или сооружения, надписи, пещерные жилища и группы элементов выдающейся универсальной ценности с точки зрения истории, искусства или науки;

Ансамбли: группы отдельных или комбинированных зданий с выдающейся универсальной ценностью с точки зрения истории, искусства или науки, единство или связь которых с архитектурой, ландшафтом;

Достопримечательности: зоны выдающейся универсальной ценности с точки зрения истории, эстетики, этнологии или антропологии, в том числе творения человеческих рук или совместной работы человека и природы, а также замечательные археологические памятники [4].

В настоящее время многие материальные и духовные памятники культуры Азербайджана охраняются ЮНЕСКО как высокие ценности человечества, например: азербайджанский мугам, азербайджанское искусство ашугов, праздник Новруз, азербайджанское ковроткачество, искусство исполнения азербайджанского тара, женский головной убор, медное искусство Лахиджа, лаваш, Ичери Шехер, комплекс Ширваншахов, Девичья башня, традиция изготовления и распространения долмы, каманча, Деде Коркут и другие. Некоторые из этих примеров вклада Азербайджана в мировое культурное наследие (например, Девичья башня, Комплекс Ширваншахов) с 2013 года имеют особый статус - имеют статус усиленной защиты - и отмечены специальной эмблемой, признанной Гаагской конвенцией 1954 года «О защите культурных ценностей в случае вооруженного конфликта». Азербайджан присоединился ко второму протоколу к этой Конвенции 12 декабря 2000 года.
Язык имеет большое значение в формировании и распространении национальных ценностей. Кроме того, язык играет важную роль в защите и приумножении национальных и духовных ценностей, их передаче из поколения в поколение. С помощью национального языка каждый народ сохраняет свою самобытность, но также знакомится с культурным наследием народов мира. В этой работе важную роль играют разные языковые единицы. Одна из таких единиц - собственные имена. Собственные имена имеют большое значение в культурном общении, в изучении культуры и традиций других народов, а также в изучении взаимосвязи языка и культуры в целом. Собственные имена - хранители материальных и духовных культурных образов конкретной общины. Они отражают национальные и культурные символы, стереотипы, стандарты, традиции и мировоззрение носителей языка. Онимы сочетают в себе национальное и культурное мировоззрение, поэтому они играют важную роль в проявлении и передаче национально-культурной специфики этноса. Потому что значение собственного имени как культурного символа разъясняется двояко:

1. соответствие имен собственных с национальнокультурными концептами;

2. интерпретация имен собственных в материальном, социальном, духовно-культурном пространстве.

Особенности национально-культурной специфики эргонимов связано с тем, что эргонимы, хотя и носят интернациональный характер, отражают национальную культуру, так как она обусловлена национально-историческими традициями народа. Это становится очевидным при соответствии эргонимов с национальными культурными концепциями и их интерпретации в контексте конкретной страны.

Очень интересно рассмотреть влияние эргонимов на человеческое сознание. Для лексического и семантического изучения эргонимов мы можем классифицировать их следующим образом:

1. эргонимы, образованные от одушевленных имен существительных;

2. эргонимы, образованные от неодушевленных имен существительных;

3. эргонимы, образованные от названий географических объектов и т. д.

Как известно, основная функция эргонимов - это индивидуализация, а также наименование. Номинаторы используют имена и фамилии всемирно известных людей, мифологических или художественных персонажей, произведений искусства для создания различных ассоциаций имен. Процесс наименования считается успешным, если выбор того или иного имени, данного номинатором, соответствует его пониманию носителем языка и специфике деятельности организации, носящей это имя. 
Эргонимы, которые мы анализируем в статье, сформированы семантически. Большинство рассматриваемых эргонимов - это следующие слова:

1. образованные трансформацией (изменением) или трансонимизацией, т.е. «Переходом одной ономастической единицы в другую» [1, с. 93]; 2) образованные онимизацией (созданием собственного имени от нарицательного).

К числу образованных в результате трансформации / трансонимизации относятся эргонимы, отражающие названия исторических памятников.

Эргонимы, образованные от названий памятников истории и архитектуры:

Ресторан «Ичери Шехер». Свое название объект получил из-за пространственной близости к древнему историческому городу Ичери Шехер. Ичери Шехер исторический памятник, который ценится не только для Азербайджана, но и как общечеловеческая ценность. Это очень ценный образец материальной культуры Азербайджана. Рекомендации «Об охране и современной роли исторических ансамблей», принятые Генеральной конференцией Организации Объединенных Наций по образованию, науке и культуре в Найроби 26 ноября 1976 года, гласят: «Исторические или традиционные ансамбли» означают неприкосновенность и ценность. Любые здания, сооружения, археологические раскопки, известные как археологические, архитектурные, исторические, эстетические и социокультурные, образующие поселения в городах, считаются открытыми пространствами. Среди этих непохожих друг на друга ансамблей выделяются исторические города и кварталы древних городов» [8]. Ичери Шехер - один из таких ансамблей. Это подтверждается включением памятника Ичери Шехер в Список всемирного наследия ЮНЕСКО.

«Речной сад Девичьей башни». Свое название объект получил потому, что находится в непосредственной близости от Девичьей башни. Девичья башня как исторический памятник является частью истории и архитектуры Азербайджана и считается образцом материального культурного наследия, принятого ЮНЕСКО. Будучи символом Баку «существуют разные мнения об истории строительства Девичьей башни. Говорят, что фундамент Девичьей башни был заложен в VII веке до нашей эры, а вторая часть была завершена в XII веке нашей эры» [6, с. 6].

Ресторан-музей «Ширваншах». Объект больше похож на музей, чем на предприятие общественного питания, возрождая уклад жизни Азербайджана 100 лет назад. «Дворцовый ансамбль Ширваншахов» является образцом декоративно-прикладного искусства средневековой азербайджанской архитектуры и принадлежал правителям государства Ширваншахов. В настоящее время это музей-заповедник. Он расположен на самой высокой точке Старого города. Считается прекрасным образцом культурного наследия XV века.

Страховая компания «Атешгях». Название «Храма огня» - «Атешгях», внесенного в Список всемирного наследия ЮНЕСКО благодаря своей оригинальности и уникальности, также может использоваться как эргоним. Атешгях - священное место, из которого выходит природный газ и горит вечное неугасимое пламя. Он был построен в XVII-XVIII веках. Как национальное достояние, зороастрийский памятник, который до сих пор является древней религией, остается первым из двух редких алтарей в мире.

Эргонимов, образованных онимизацией, в свою очередь можно классифицировать следующим образом:

Эргонимы, отражающие исполнительское искусство:

Международный центр мугама. Это заведение, где проходят фестивали и конкурсы мугама. «Ученые относят создание мугама, великолепного памятника восточной музыки, к последнему тысячелетию, доисламскому периоду. Его корни связаны с зороастризмом. Значение слова мугам также объясняется как музыка, посланная Богом. Также сказано, что мугам очищает души людей силой Бога» [2, с. 139].

Ресторан «Мугам Клуб». Этот объект находится в здании XVII века - Караван-сарае. В прошлом Караван-сарай был самым популярным местом для торговых караванов, прибывающих в Азербайджан, чтобы переночевать и отдохнуть. Название ресторана всегда связано со звучанием старинного мугама. Мугам - это культурное наследие, имеющее большую ценность как для национальной, так и для мировой культуры. Принимая это во внимание, в 2003 году ЮНЕСКО включила мугам в свой список.

Ресторан «Оху, тар». Этот эргономичный текст привлекает внимание двумя способами:

1. содержит слово tar;

2. это название очень известного стихотворения известного азербайджанского поэта Микаила Мушфига.

Известно, что одним из самых распространенных струнных музыкальных инструментов в Азербайджане является тар. Тар является одновременно аккомпанементом и сольным инструментом. На нем играют мизрабом. В переводе с персидского «tar» означает проволока. Тар был впервые изготовлен в Х веке в деревне Фараб города Карки Мухаммедом, сыном Тархана, одного из туркестанских тюрок. Во второй половине XIX века азербайджанский тарист Мирза Садыг (Садыгджан) внес изменения в структуру и форму тара. Он поднес тар с колен к груди. Именно улучшенный им азербайджанский тар широко распространен на Кавказе и в Средней Азии. Модернизация тара сыграла важную роль в развитии мугамов. 
«Узеир Гаджибейли заложил основы музыкального исполнительства, включив в эту оперу наш национальный инструмент - тар (в опере «Лейли и Меджнун» - К.Т.)» [3].

Символическое название ресторана «Оху, тар» также связано с его расположением в саду Микаила Мушфига. Другими словами, этот эргоним также является ономастической единицей, основанной на прецедентном тексте.

Стоит отметить, что конструкции из тара также используются в народном зодчестве. Например, здание Международного центра мугама напоминает по форме этот старинный музыкальный инструмент.

«Kaman House». Каманча, струнный музыкальный инструмент с впечатляющим тембром, изображен в стихотворении Низами Гянджеви «Хосров и Ширин» и в миниатюрных картинах Тебриза. Изготовление каманчи и исполнительское искусство были включены в список нематериального культурного наследия ЮНЕСКО, нуждающегося в срочной защите.

\section{Эргонимы, отражающие традиционное мастерство:}

Ресторан «Ковер». Наименование этого эргонимов - слово «ковер». Включение азербайджанского ковра в Репрезентативный список нематериального культурного наследия человечества ЮНЕСКО показывает, что ковры, сотканные и произведенные в Азербайджане, считаются уникальными в мире. Возникновение и развитие азербайджанского коврового искусства - неотъемлемая часть национальной культуры. Согласно исследованиям, искусство ковроткачества зародилось в Азербайджане в эпоху бронзы, развивалось и обогащалось. На самом деле ковроткачество широко распространено в ряде стран мира, но можно с уверенностью сказать, что Азербайджан является колыбелью этого искусства.

«Кялагаим», «Семь прекрасных кялагаи». Кялагаи - это шелковой головной убор в Азербайджане. Он изготовлен из шекинского шелка. На протяжении многих лет Шеки был центром производства шелка не только в Азербайджане, но и на Кавказе в целом. Хотя калагаи древний вид одежды, все еще широко распространен. Искусство будущего Азербайджана внесено в Репрезентативный список ЮНЕСКО. С этим образцом культурного наследия связаны названия таких объектов, как «Кялагаим», «Семь прекрасных калагаи».

\section{Эргонимы, отражающие социальный опыт:}

Ресторан «Долма». У каждого народа своя история, национальные костюмы, музыкальные инструменты, а также кулинарное искусство. Это особенности, которые отличают каждую этническую группу. Азербайджанская кухня - одна из старейших, богатейших и вкуснейших ку- хонь мира. Важнейшими факторами, влияющими на его создание и развитие, являются климат, историческое и географическое положение людей, их взаимодействие с соседними народами. Азербайджанская кухня, наряду с сочетанием методов приготовления, также является ключевой частью материальной культуры. Сегодня в национальной кухне известно около 2000 видов блюд. В эргономичном пространстве много эргонимов, сделанных из названий блюд древней азербайджанской кухни. Название ресторана «Долма» - одно из таких эргономичных наименований. Долма - образец общетюркской национальной кухни. Долма является своеобразным историческим памятником для азербайджанских тюрок. У каждого народа есть блюдо, с помощью которого можно определить национальность. Долма - такое блюдо для азербайджанцев.

В Азербайджане 2 из 11 элементов, включенных в Список всемирного нематериального культурного наследия ЮНЕСКО, связаны с блюдами национальной кухни: лаваш (2016 г.) и долма (2017 г.).

Ресторан «Лаваш» над очагом. Хлеб - самое святое благословение азербайджанской кухни. Название лаваша - один из самых распространенных видов хлеба в национальной кухне. История лаваша восходит к глубокой древности. Лаваш поздно портится и поэтому занимает особое место в элатской культуре. Это по-прежнему один из самых использованных продуктов.

Образовательный фонд «Симург». Птица Симург также является одним из примеров нематериального культурного наследия Азербайджана. По легенде птица Симург считалась символом бессмертия, способности лечить все болезни. Это древний символ доброты, новой жизни и возрождения в азербайджанской мифологии, образ, выводящий людей из тьмы к свету. Образовательный фонд «Симург» создан для помощи детям, особенно детям шехидов и ветеранов, в решении вопросов, связанных с образованием. Его основная миссия - изменить и осветить жизнь детей через образование.

Есть несколько основных функций, которые являются общими для эргонимов в данном исследовании:

1. номинативная;

2. отличительная;

3. индивидуализирующая;

4. информативная или идентифицирующая;

5. рекламная;

6. защитная.

Основная задача эргонимов - придать индивидуальность оказываемым на объекте услугам. Следовательно, номинативная функция - самая важная функция. Эта функция особенно важна для конкурирующих торговых объектов. Несомненно, не следует забывать об инди- 
видуализирующих и отличительных функциях. Информационная или идентифицирующая функция анализируемых эргонимов тесно связана с вышеуказанными функциями. Эргонимы включают слова и выражения, содержащие культурную и историческую информацию.

Поскольку большая часть приведенной в статье эргонимов - это торговые объекты, они также выполняют функцию рекламы. Рекламная функция также тесно связана с информативностью. В результате этой функции создаются образы, оказывающие сильное влияние на психику реципиента.

Защитная функция эргонимов связана с изображением объекта. Эти эргонимы выполняют функции традиционной индивидуализации, рекламную и информативную функции, а также функцию защиты собственности. Они также являются носителями и передатчиками национальной культуры и мировоззрения.

Обращаем внимание на результаты нашего исследования. Прежде всего, следует отметить, что собственные имена в азербайджанской ономастике до сих пор не были объектом комплексного лингвокультурологического исследования.

Эргонимы богаты многогранной энциклопедической информацией. Эта информация обусловлена языком и традициями народа. Эргонимы очень информативны для изучения лингвокультуры. Здесь языковые характеристики определяются экстралингвистическими фак- торами: национально-культурными, экономическими, правовыми.

Названия торговых объектов представляют собой динамично развивающуюся группу эргонимов, характеризуют ономастическое пространство современного города, имеют лингвокультурное значение. Они отражают активные языковые процессы. Наименование торговых объектов обусловлено активными языковыми процессами и прагматической целью номинатора.

Эргонимы современных городов отражают уникальность их культурной и языковой среды. Поскольку эргономическое пространство обогащается средствами национального языка, здесь можно актуализировать национально-культурные компоненты.

В результате анализа эргонимов можно сказать, что раскрытие базовой лексемы происходит на фоне дополнительной информации об объекте. Эта дополнительная информация включает тип объекта и его совместимость с другими объектами, а также восприятие названия человеком. В статье определены критерии мотивации номинатора при выборе или создании эргонима:

1. выбор имен в соответствии с их функцией и социальным назначением;

2. выбор имен по эмоциям и образным выражениям.

Изучение эргонимов с когнитивной, лингвокультурной и социально-ономастической точек зрения является многообещающим для будущих исследований.

\section{ЛИТЕРАТУРА}

1. Həbibli R. Tətbiqi onomastika məsələləri. Bakı: MSV Nəşr, 2018.

2. Muğam ensiklopediyası. Bakı: Musiqi dünyası, 2008.

3. Novruzov A. Üzeyir Hacıbəyli və xalq çalğı alətlərində not ifaçllı̆ı. Konservatoriya, 4, 2015 // http://konservatoriya.az/?p=1364

4. UNESKO-nun “Ümumdünya mədəni irsin və təbii sərvətlərin qorunması haqqında” 16 noyabr 1972-ci il tarixli Konvensiyası (maddə 1) // https://unesco.preslib. $\mathrm{az} / \mathrm{az} / \mathrm{page} / \mathrm{ZkBp} 5 \mathrm{YPq} 2 \mathrm{~F}$

5. "Silahlı Münaqişə Zamanı Mədəni Sərvətlərin Mühafizəsi haqqında Konvensiya və iki protokol" 1954-cü il tarixli Haaqa Konvensiyası // azerbaijan_ latalph_1954HCP1.pdf - UNESCO www.unesco.org

6. Sultanova P. Qız Qalası: qədim və əbədi daş möcüzə. 525-ci qəzet. 6 may 2011, s.6.

7. Подольская Н.В. Словарь русских ономастических терминов. Москва, Наука, 1988.

8. Рекомендация о сохранении и современной роли исторических ансамблей от 26 ноября 1976 г. // http://docs.cntd.ru/document/901756972

( Тагиева Кенуль Арзу гызы (konul.t@rambler.ru). 